SYMPOSIUM ON EVIDENCE BASED MEDICINE

\title{
Ethical problems arising in evidence based complementary and alternative medicine
}

\author{
E Ernst, M H Cohen, J Stone
}

J Med Ethics 2004;30:156-159. doi: 10.1136/ime.2003.007021

Complementary and alternative medicine has become an important section of healthcare. Its high level of acceptance among the general population represents a challenge to healthcare professionals of all disciplines and raises a host of ethical issues. This article is an attempt to explore some of the more obvious or practical ethical aspects of complementary and alternative medicine.

See end of article for authors' affiliations

Correspondence to: Professor E Ernst, Complementary Medicine, Peninsula Medical School, Universities of Exeter and Plymouth, 25 Victoria Park Road, Exeter EX2 4NT, UK; Edzard.Ernsł@ pms.ac.uk

Received

13 November 2003 Revised version received 13 November 2003 Accepted for publication 27 November 2003
$\mathrm{T}$ he popularity of complementary and alternative medicine (CAM) is considerable: the one year prevalence of CAM usage is $42 \%$ in the United States ${ }^{1}$ and $20 \%$ in the United Kingdom. ${ }^{2}$ As it turns out, at first glimpse, there are very few differences between the ethics of conventional medicine and those of CAM. ${ }^{3-5}$ In fact, many of the ethical rules applicable to conventional medicine-such as requirements of informed consent, practice boundaries (that is, the duty to practice within one's scope of competence or else to appropriately refer), and duties involving confidentiality and privacytranslate across to the arena of CAM. ${ }^{6}$ In addition, much of the regulatory framework governing conventional medicine, which incorporates many ethical obligations, also translates to CAM practice. This includes, for example, licensure, malpractice liability rules, and legal rules governing professional discipline. ${ }^{7}$ The focus of this article is therefore on ethical aspects in areas of overt variations between CAM and conventional medicine. Because considerable national differences may exist, our article primarily focuses on CAM in the UK.

\section{DEFINITION}

A definition of CAM is far from easy. CAM is an umbrella term for numerous diagnostic and therapeutic methods that lie outside orthodox medicine. Most definitions therefore describe CAM by what it is not rather than by what it is (for example, not taught in medical schools, not scientifically proven, not plausible, not in line with the concepts of orthodox medicine, etc). Such definitions are of questionable value and validity; for instance, several forms of CAM are now taught in some medical schools ${ }^{8}$ or are recognised, by many biomedical practitioners, as having a sufficient evidence base for recommendation by physicians ${ }^{9}$ (for example, medical herbalism). ${ }^{10}$

In an attempt to find a positive definition, we have suggested the following: CAM is "diagnosis, treatment and/or prevention which comple- ments mainstream medicine by contributing to a common whole, by satisfying a demand not met by orthodoxy or by diversifying the conceptual frameworks of medicine". ${ }^{11}$ This definition of CAM has now been adopted by the Cochrane Collaboration's "field" in CAM. It is, however, academic and does not describe the modalities involved. Table 1 provides a brief description of some of the most important therapeutic methods within CAM.

\section{DIFFERENCES BETWEEN CAM AND CONVENTIONAL MEDICINE}

For the purpose of this article, it may be helpful to highlight some of the major, current conceptual and pragmatic differences between CAM and conventional medicine, particularly those with implications concerning ethical obligations. In doing so, a degree of simplification and dichotomisation may be necessary, recognising that CAM research and practice are both evolving; that definitions embrace legal, social, and political (as well as medical and scientific) realities, ${ }^{12}$ and that the lines between conventional medicine and CAM become blurred when CAM therapies are incorporated into routine medical practice.

In this light, some of the most visible differences between CAM and conventional medicine currently include:

- In many countries (for example, the UK), CAM is predominantly private medicine and not normally reimbursed within the official healthcare system.

- Providers of CAM often lack significant medical training, and usually (in the UK) are not physicians who have gone through medical school.

- Non-medical CAM providers generally have their own licensing laws, or frequently (in the UK) operate outside medical licensing laws.

- The effectiveness and safety of many forms of CAM is under researched relative to much of orthodox medicine and often not proven, according to the standards currently adopted in conventional medicine.

- Research funds for CAM are currently scarce, much more so than in conventional medicine.

- CAM lacks a tradition or culture of modern, scientific research comparable to conventional medicine.

Abbreviations: BMA, British Medical Association; CAM, complementary and alternative medicine. 
Table 1 Examples of complementary and alternative medicine

\begin{tabular}{|c|c|}
\hline $\begin{array}{l}\text { Name of } \\
\text { therapy }\end{array}$ & Brief description \\
\hline Acupuncture & $\begin{array}{l}\text { Stimulation of acupuncture points by inserting a needle, } \\
\text { electrical current (electroacupuncture), heat (moxibustion), } \\
\text { laser (laser acupuncture), or pressure (acupressure) }\end{array}$ \\
\hline $\begin{array}{l}\text { Alexander } \\
\text { technique }\end{array}$ & $\begin{array}{l}\text { Psychophysical re-education for improving posture and } \\
\text { coordination }\end{array}$ \\
\hline romatherapy & $\begin{array}{l}\text { ypplication of "essential" oils from plants, usually } \\
\text { through gentle massage }\end{array}$ \\
\hline $\begin{array}{l}\text { Autogenic } \\
\text { training }\end{array}$ & Autosuggestive, self hypnotic technique for relaxation \\
\hline & Intravenous infusion of EDTA for arteriosclerotic diseases \\
\hline Chirop & $\begin{array}{l}\text { A system of healthcare which is based on the belief that } \\
\text { the nervous system is the most important determinant of } \\
\text { health and that most diseases are caused by spinal } \\
\text { subluxations which respond to spinal manipulation. }\end{array}$ \\
\hline $\begin{array}{l}\text { Enzyme } \\
\text { therapy }\end{array}$ & $\begin{array}{l}\text { Oral administration of proteolytic enzymes aimed at } \\
\text { increasing wellbeing }\end{array}$ \\
\hline $\begin{array}{l}\text { Flower } \\
\text { remedies } \\
\text { (Bach) }\end{array}$ & $\begin{array}{l}\text { Highly dilute plant infusions to balance physical and } \\
\text { emotional disturbances }\end{array}$ \\
\hline & $\begin{array}{l}\text { The medicinal use of preparations that contain exclusively } \\
\text { plant material }\end{array}$ \\
\hline Homoeopathy & $\begin{array}{l}\text { System of medicine developed about } 200 \text { years ago by } S \\
\text { Hahnemann based on the "like cures like" principle, often } \\
\text { using extremely high dilutions }\end{array}$ \\
\hline Hypnotherapy & $\begin{array}{l}\text { Form of cognitive information processing using } \\
\text { suspension of peripheral awareness aimed at apparently } \\
\text { involving changes in perception, memory, mood, and } \\
\text { psychology }\end{array}$ \\
\hline Massage & $\begin{array}{l}\text { Manual techniques of rubbing, stroking, tapping, or } \\
\text { kneading the body with a view to treating physical or } \\
\text { emotional conditions }\end{array}$ \\
\hline Osteopathy & $\begin{array}{l}\text { Form of manual therapy involving massage, mobilisation, } \\
\text { and manipulation }\end{array}$ \\
\hline Reflexology & $\begin{array}{l}\text { Use of manual pressure to specific areas (typically on the } \\
\text { sole of the foot) thought to be related to inner organs }\end{array}$ \\
\hline Relaxation & $\begin{array}{l}\text { Eliciting a relaxation response (release of physical and } \\
\text { mental tension); often included in broader therapeutic } \\
\text { programmes }\end{array}$ \\
\hline $\begin{array}{l}\text { Spiritual } \\
\text { healing }\end{array}$ & $\begin{array}{l}\text { Channelling of "healing energy" from an external source } \\
\text { (for example, God) through the healer to the patient with } \\
\text { a view to enhancing health and wellbeing }\end{array}$ \\
\hline Tai chi & $\begin{array}{l}\text { A system of movements and postures used to enhance } \\
\text { mental and physical health }\end{array}$ \\
\hline & Stretching exercises for breathing control and meditation \\
\hline
\end{tabular}

- CAM is claimed to be holistic and, at times, benefits of CAM are thought to be mental, psychological, spiritual, and social; thus they can be less tangible or measurable than those of conventional medicine.

\section{CAM IS PRIVATE MEDICINE}

Virtually all surveys on this topic show that, in industrialised countries, CAM users tend to belong to the affluent, well educated classes ${ }^{12}$ : CAM is by and large private medicine for which consumers pay substantial amounts out of their own pockets. ${ }^{1}$ Assuming that CAM does more good than harm, this situation is far from equitable. The unequal distribution of CAM within the population violates the fundamental ethical principle of justice. Stone and Matthews put it succinctly: "...the benefits of CAM should be freely available to all...". ${ }^{13}$

The obvious way to remedy this problem is to render the distribution of CAM more even across all socioeconomic classes. However, this is likely to fail for at least two reasons: firstly, the already tight resources in healthcare are not sufficient to allow everyone free access to CAM. Secondly, permitting such general access within an evidence based healthcare system would require that the evidence for the safety and efficacy of CAM be more solid than is presently the case (see below). ${ }^{10}$ As long as efficacy and safety of CAM are uncertain (that is, significantly more uncertain than in conventional medicine), the principle of justice may be in conflict with the principles of beneficence and non-maleficence. $^{3}{ }^{13}$ There is no easy solution to this dilemma-other than swiftly conducting the research that is necessary to establish efficacy and safety.

\section{PROVIDERS OF CAM ARE OFTEN NOT MEDICALLY TRAINED}

The vast majority of CAM providers in the UK are nondoctors. Most CAM providers, one would hope, have adequate training in the methods they practice but their understanding of anatomy, physiology, pathology, and other disciplines of Western medical science may be limited, and many may adhere to views or philosophies or perspectives (for example, the notion of acupuncture "meridians" in traditional Chinese medicine) which are in overt contradiction to the concepts, principles, and accepted facts of conventional medicine and science. These differences of view-and, from the perspective of dominant perspectives in Western medicine, limitations of understanding-create several ethically relevant questions. How can practitioners of CAM meaningfully communicate with practitioners of conventional medicine and vice versa? If communication is suboptimal, does that have the potential to put patients at risk? Is the limited medical knowledge of some CAM providers a risk factor for their patients? Is the limited CAM knowledge of conventional physicians a risk factor for patients? From the perspective of mainstream medicine, do CAM providers view the potential limitations of their own methods realistically? The ethical principle that may be at stake here is that of non-maleficence. ${ }^{3}{ }^{13}$ Currently there is little research into the questions raised above and conclusive answers are therefore not possible. Allegations of violations of the principle of non-maleficence obviously run on both sides of the debate.

\section{CAM (AT LEAST IN THE UK) IS NOT REGULATED AS RIGOROUSLY AS CONVENTIONAL MEDICINE}

Stone and Matthew point out that the aims of professional self regulation are to ensure: (1) high, uniform standards of practice; (2) identification of competent practitioners, and (3) accountability. ${ }^{13}$ Essentially they relate to the ethical principle of non-maleficence. Unlike the situation of widespread licensure in the US for chiropractors, acupuncturists, massage therapists, and, to some extent, naturopathic physicians, ${ }^{7}$ most CAM professions in the UK are not statutorily regulated (the only two exceptions in the UK are chiropractors and osteopaths). In the UK, several professional bodies of acupuncture, homeopathy, medical herbalism, and others do exist. Yet it is not obligatory to belong to them, and essentially anyone (regardless of education, training, or background) could set up as an acupuncturist, homeopath, herbalist, etc.

This situation creates serious ethical questions similar to the ones mentioned previously. If someone practices acupuncture, homeopathy, herbalism, or other with insufficient training, to what extent are they likely to put patients at risk? If a CAM provider does not belong to a professional organisation, to whom do their patients complain if they feel badly treated? How far do unregulated CAM providers adhere to essential ethical issues such as informed consent, confidentiality, and maintaining appropriate boundaries?

Stone and Matthews discuss the strengths and weaknesses of statutory self regulation and voluntary self regulation. ${ }^{13}$ They conclude that for therapies unlikely to cause direct physical harm, the latter is a "cheaper and more flexible means of achieving the same regulatory aims". Perhaps it is 
less important how these aims are reached than the fact that they are reached.

Informed consent is a particularly complex issue. ${ }^{14}$ The World Medical Association's Declaration of Lisbon (1981) states the fundamental position that "the patient has the right to accept or refuse treatment after receiving adequate information". ${ }^{15}$ This raises, among other issues, the question: what is adequate information? The answer provided by the British Medical Association (BMA) is "what the average prudent patient would want to know". ${ }^{15}$ As a minimum (one would assume) patients want to know about serious but rare and mild yet common adverse effects, as well as about other therapeutic options. ${ }^{14}$ The crucial question here is, do CAM practitioners routinely provide that information, and how do they interpret what the average, prudent patient would want to know? A recent US survey was aimed at determining what the average patient requires. Of 2500 patients, $76 \%$ wanted to be told of all possible adverse effects regardless of incidence. Only 13\% wanted know about adverse effects with a prevalence of 1:100 000 and only $10 \%$ wanted to know about adverse effects with a prevalence of $1: 100 .^{16}$

The potential interactions of various treatments are an example of the challenge to the practice of informed consent in CAM. Interactions of herbal and conventional medicines exist but are under researched and thus often unknown. ${ }^{17}$ It is essential that conventional physicians and CAM practitioners make themselves aware of whatever complementary treatments the patient pursues in order to advise on the risk - to the extent known-of unwanted interactions. Truly informed consent may therefore be impossible to achieve. The question then arises to what extent, if any, should patients be protected from making potentially self harming choices? How should consent be determined when the risks are unknown? Should consent be allowed in last resort therapies, where the potential risks are appreciable but the patient is prepared to go ahead nonetheless?

\section{THE EFFECTIVENESS AND SAFETY OF CAM ARE OFTEN CONSIDERED UNPROVEN}

Many consumers may be attracted to CAM because they assume that CAM is effective and almost free of risk. For some types of CAM this may well be true. However, for the majority of CAM modalities finite risks exist; at the same time our knowledge is insufficient for conducting reliable risk benefit analyses. ${ }^{10}$ In other words, in many areas of CAM we have so far insufficient evidence to state with confidence that more good than harm is being done.

Obviously this means that more research is required to define both risk and benefit more accurately. But until it is available, clinical CAM practice operates in the presence of uncertainty. Uncertainty is not an unusual factor in medicine. The point, however, is that the level of uncertainty in CAM is considerably greater than that of conventional medicine. This means that CAM users might not experience the benefit they were led to believe. In other words, the ethical principles of beneficence and non-maleficence could be violated in an unpredictable way and with unknown frequency. One solution to this quandary is the application of legal sanction to cases of excessive claims, exaggerated promises, and deception and fraud..$^{18}$

And how can more research be done within CAM? It seems that changes are required on several levels. The need for CAM research requires widespread recognition, not least by CAM practitioners. Career scientists should be attracted to CAM research to provide scientific expertise where it presently is underdeveloped. Adequate research funds must be made available to fuel this process. From a UK perspective, it is interesting to observe how the availability of research funds in the US has driven the process towards more and methodologically sounder research in that country. Rigorous research is certainly not confined to randomised clinical trials. For defining the safety of CAM, for instance, other methodologies (for example, post marketing surveillance studies) are much more adequate. Generally speaking, the research question determines the optimal research methodology. ${ }^{19} 20$

\section{RESEARCH FUNDS ARE SCARCE}

Funds are scarce for CAM research compared with most areas of medical research. ${ }^{21}$ Governments and other funding bodies usually allocate health resources on the basis of existing evidence. ${ }^{22}$ Because the evidence for CAM is fragmentary and evolving, research applications in CAM-other than to government agencies specifically created to fund CAM research, such as the (rather unique) National Center for Complementary and Alternative Medicine (NCCAM) at the NIH in the US-have a lower chance of receiving funding than those in conventional medicine. This situation creates a systemic bias, which results in allocation of resources to those areas of (conventional) medicine for which reasonably good evidence already exists. The resulting funding stream is at the expense of areas in which no or less evidence currently exists-for example, CAM. ${ }^{23}$ This impinges on the ethical principle of justice. In principle, it also perpetuates the under researched status of CAM.

\section{CAM HAS AN UNDERDEVELOPED RESEARCH CULTURE}

Because CAM historically has lacked the established research infrastructure of conventional medicine, it has attracted relatively few high calibre researchers. As a consequence, the field suffers from a general lack of research expertise (potentiated and perpetuated by lack of funds). This, in turn, has resulted in a situation where many of the relatively few scientific investigations in CAM are methodologically weak, or outright flawed. ${ }^{24}$ Yet flawed science is unlikely to be ethical ${ }^{25}$ : expressed in the words of the BMA, "Studies which are unscientific are also unethical". ${ }^{13}$

In recent years the Cochrane Collaboration has established a "field" in CAM. ${ }^{26}$ Essentially this facilitates systematic reviews of clinical trials in a diverse range of medical disciplines. Some 50 such reviews are now available on the Cochrane database and a substantial proportion yield positive or encouraging results about the efficacy of CAM modalities in defined medical conditions. Thus the Cochrane Collaboration has made an important contribution to a research culture in CAM. What seems to be missing at present is that the CAM community at large takes these advances on board.

Today, research ethics committees have the remit to watch over medical research including that in CAM. Some of the core points they must consider include. ${ }^{13}$

- scientific quality of proposal

- competence of investigators

- risks for study participants

- informed consent

- indemnity cover

- financial rewards to subjects or investigators

- data protection.

Because of the lack of a vibrant research culture in CAM, many CAM researchers find it difficult or even impossible to compose research applications that would pass the scrutiny of a research ethics committee. Anecdotally, we also suspect that some ethics committees have in the past been biased against CAM research. This further hinders an active research 
culture from emerging. Alternatively it may have the effect that some researchers-unless required by prevailing legal rules-may not submit their projects to any ethics committee for approval. Overtly unethical research might therefore be conducted in CAM. ${ }^{27}$ Ethics committees often have insufficient knowledge about CAM which renders a fair judgment on such research proposals difficult and further impedes CAM research.

In order to promote the growth of a CAM research culture, the attitudes among CAM practitioners and the skepticism of research ethics committees both need to be overcome. This will involve a process of learning and education. CAM practitioners have to understand the value of science and the fact that without scientific proof CAM is unlikely to survive. Scientifically minded evaluators of CAM projects should understand the nature of CAM and the fact that, in certain instances, scientific rigor can only be taken to a certain point.

\section{CAM IS HOLISTIC}

Many proponents of CAM are keen to point out the holistic nature of CAM and claim that some of its therapeutic benefits may occur on levels not readily accessible by quantitative measurements. The whole ethos of evidence based medicine, however, crucially depends on reproducible, quantifiable outcomes. What is not measurable tends to be denied existence. This situation may create an ethically questionable bias within mainstream medicine against areas of medicine in which outcomes cannot be adequately quantified or defined. ${ }^{23}$ Moreover, the "clash in paradigms" makes it difficult to compare "evidence" across conventional and CAM therapies: CAM may have notions of efficacy that operate on different principles and on spiritual, rather than solely physical, levels.

\section{COMMENT}

The ethical problems encountered in CAM rarely differ significantly from those of other areas of medicine. Principles from which positive duties emerge include beneficence, a duty to promote good and act in the best interest of the patient and the health of society, and nonmaleficence-the duty to protect and do no harm to patients. Also included is respect for patient autonomy-the duty to foster a patient's informed, uncoerced choices. ${ }^{28}$ From the principle of respect for autonomy are derived the rules for truth telling, disclosure, and informed consent. On one hand, the relative weight granted to these principles and the conflicts among them often account for the ethical problems that CAM practitioners (as well as conventional health practitioners) face. Moreover, as research demonstrates safety and/or efficacy of one or more CAM therapies, such therapies become incorporated into conventional practice and could thus cease being seen as CAM.

On the other hand, some of the cultural, legal, and political factors presently differentiating mainstream medical from CAM practice create unique ethical issues that current research has only begun to address. Furthermore, many CAM therapies have philosophical underpinnings that challenge orthodox medical perspectives, and thus hinder attempts at scientific validation with conventional methodologies. It is, however, quite clear that such challenges are not a complete block to good CAM research. As stated above, the research question determines the choice of the research methodology, ${ }^{19} 20$ and there are no reasons in principle why rigorous CAM research cannot be undertaken. Ultimately, political questions (such as who should have access to therapies and under what circumstances) and values (such as autonomy and medical pluralism, and developments in clinical practice), based on increasing communication between conventional and CAM providers, may shape the ethical landscape as much as scientific research and evolving legal rules.

\section{Authors' affiliations}

E Ernst, Complementary Medicine, Peninsula Medical School, Universities of Exeter and Plymouth, Exeter, UK

M H Cohen, Director, Legal Programs, Harvard Medical School Osher Institute, Fortieth Anniversary Senior Scholar at the Center for World Religions, Harvard Divinity School, Boston, MA, USA

J Stone, Freelance writer and lecturer, Amersham, UK

\section{REFERENCES}

1 Eisenberg DM, David RB, Ettner SL, et al. Trends in alternative medicine use in the United States. JAMA 1998;280:1569-75.

2 Ernst E. White AR. The BBC survey of complementary medicine use in the UK. Complement Ther Med 2000;8:32-6.

3 Ernst E. The ethics of complementary medicine. J Med Ethics 1996;22:197-8.

4 Stone J. An ethical framework for complementary and alternative therapies. London: Routledge, 2002.

5 Cohen MH. Beyond complementary medicine. Ann Arbour, MI: University of Michigan Press, 2000.

6 Cohen MH. Future medicine: ethical dilemmas, regulatory challenges, and therapeutic pathways to health and healing in human transformation. Ann Arbour, Ml: University of Michigan Press, 2003.

7 Cohen $\mathrm{MH}$. Complementary and alternative medicine: legal boundaries and regulatory perspectives. Baltimore, MD: Johns Hopkins University Press, 1998.

8 Wetzel MS, Eisenberg DM, Kaptchuk TJ. Courses involving complementary and alternative medicine in US medical schools. JAMA 1998;280:784-6.

9 Cohen MH, Eisenberg DM. Potential physician malpractice liability associated with complementary and integrative medicine therapies. Ann Intern Med 2002; 136:596-603.

10 Ernst E, Pittler MH, Stevinson C, et al. The desktop guide to complementary and alternative medicine. Edinburgh: Mosby, 2001.

11 Ernst E, Resch KL, Mills S, et al. Complementary medicine-a definition. Br J Gen Pract 1995:45:506.

12 Kaptchuk TJ, Eisenberg DM. Varieties of healing. 1: medical pluralism in the United States, Ann Intern Med 2001;135:189-95.

13 Stone J, Matthews J. Complementary medicine and the law. Oxford: Oxford University Press, 1996.

14 Ernst $\mathrm{E}$, Cohen $\mathrm{MH}$. Informed consent in complementary and alternative medicine. Arch Intern Med 2001;161:2288-92.

15 BMA. Medical ethics today. London, 1993.

16 Ziegler DK, Mosier MC, Buenaver M, et al. How much information about adverse effects of medication do patients want from physicians? Arch Intern Med 2001;161:706-13.

17 Izzo AA, Ernst EE. Interactions between herbal medicines and prescribed drugs: a systematic review. Drugs 2001;15:2163-75.

18 Cohen MH. A fixed star in health care reform: the emerging paradigm of holistic healing. Ariz State L J 1995;27:79-173.

19 Sackett DL, Wennberg JE. Choosing the best research design for each question. BMJ 1997;315:1636.

20 Vickers A, Cassileth B, Ernst E, et al. How should we research unconventional therapies? A panel report from the conference on Complementary and Alternative Medicine Research Methodology, National Institute of Health. Int J Technol Assess Health Care 1997;13:111-21.

21 Ernst E. Funding research into complementary medicine: the situation in Britain. Complement Ther Med 1999;7:250-3.

22 Eddy DK. Benefit language; criteria that will improve quality while reducing cost. JAMA 1996;27:650-7.

23 Kerridge J, Lowe M, Henry D. Ethics and evidence based medicine. BMJ 1998;316:1151-3

24 Linde K, Jonas WB, Melchart D, et al. The methodological quality of randomised controlled trials of homeopathy, herbal medicine and acupuncture. Int J Epidemiol 2001;30:S26-31.

25 Freedman B. Scientific value and validity as ethical requirements for research: a proposed explanation. IRB: A review of human subjects 1987;17:7-10.

26 Ezzo J, Berman BM, Vickers AJ, et al. Complementary medicine and the Cochrane Collaboration. JAMA 1998;280:1628-30.

27 Ernst E. Research ethics questioned in Qigong study. Alternative Ther 2002;8:18-19.

28 Beauchamp TL, Childress JF. Principles of biomedical ethics, 4th ed. New York: Oxford University Press, 2002. 